\title{
Human salivary gland stem cells ameliorate hyposalivation of radiation-damaged rat salivary glands
}

\begin{abstract}
Jaemin Jeong ${ }^{1,5}$, Hyunjung Baek ${ }^{1,5}$, Yoon-Ju Kim ${ }^{1}$, Youngwook Choi ${ }^{1}$, Heekyung Lee ${ }^{1}$, Eunju Lee ${ }^{1}$, Eun Sook $\mathrm{Kim}^{1}$, Jeong Hun $\mathrm{Hah}^{2}$, Tack-Kyun Kwon ${ }^{2}$, Ik Joon Choi ${ }^{3}$ and Heechung Kwon ${ }^{1,4}$

Salivary function in mammals may be defective for various reasons, such as aging, Sjogren's syndrome or radiation therapy in head and neck cancer patients. Recently, tissue-specific stem cell therapy has attracted public attention as a next-generation therapeutic reagent. In the present study, we isolated tissue-specific stem cells from the human submandibular salivary gland (hSGSCs). To efficiently isolate and amplify hSGSCs in large amounts, we developed a culture system (lasting 4-5 weeks) without any selection. After five passages, we obtained adherent cells that expressed mesenchymal stem cell surface antigen markers, such as CD44, CD49f, CD90 and CD105, but not the hematopoietic stem cell markers, CD34 and CD45, and that were able to undergo adipogenic, osteogenic and chondrogenic differentiation. In addition, hSGSCs were differentiated into amylase-expressing cells by using a two-step differentiation method. Transplantation of hSGSCs to radiation-damaged rat salivary glands rescued hyposalivation and body weight loss, restored acinar and duct cell structure, and decreased the amount of apoptotic cells. These data suggest that the isolated hSGSCs, which may have characteristics of mesenchymal-like stem cells, could be used as a cell therapy agent for the damaged salivary gland.
\end{abstract}

Experimental \& Molecular Medicine (2013) 45, e58; doi:10.1038/emm.2013.121; published online 15 November 2013

Keywords: amylase; hyposalivation; radiation-induced damage; salivary gland; stem cells

\section{INTRODUCTION}

The salivary glands produce saliva, which contains several enzymes that have a crucial role in the digestion of food, especially starches and fats. ${ }^{1}$ However, hyposalivation may be caused by aging, ${ }^{2}$ Sjogren's syndrome ${ }^{3}$ or radiation therapy in head and neck cancer patients. ${ }^{4}$ Salivary gland hypofunction that reduces the flow of saliva decreases the quality of life by degrading dental and oral health., ${ }^{5,6}$ In particular, radiationinduced salivary gland hypofunction has been observed in more than $60 \%$ of head and neck cancer patients undergoing radiotherapy. ${ }^{7-9}$ Therefore, prevention and treatment of hyposalivation in this population is very important.

Adult stem cells have been isolated from numerous organs in the body ${ }^{10}$ and differentiated into target cell lineages, and they have thus been used as a therapeutic agent for many years. ${ }^{11,12}$ Mesenchymal stem cells (MSCs) isolated from the umbilical cord, ${ }^{13}$ adipose tissue, ${ }^{14}$ lung tissue ${ }^{15}$ and bone marrow ${ }^{16}$ have been used for healing applications because of their capacity for tissue regeneration, ${ }^{17,18}$ trophic support ${ }^{19-21}$ and modulation of the innate immune response. ${ }^{22}$ Although they exhibit many common characteristics, some studies have shown important differences according to their origin with regard to morphology, colony formation, differentiation capacity and therapeutic effect. ${ }^{23-26}$ For example, fat-derived MSCs exhibit better adipogenic differentiation than do bone marrow or placental MSCs, which suggests that origin-specific MSCs are favorable for treatment of the tissue of origin..$^{27}$

In the present study, to ameliorate hypofunction of the radiation-damaged salivary gland, we developed a culture system for isolation of human salivary gland stem cells (hSGSCs) that requires $4-5$ weeks, and we demonstrated for the first time that the differentiation capacities of these cells can be used as a therapeutic agent for the damaged salivary gland.

\footnotetext{
${ }^{1}$ Division of Radiation Oncology, Korea Institute of Radiological and Medical Sciences, Seoul, Korea; ${ }^{2}$ Department of Otorhinolaryngology, Seoul National University Hospital, Seoul, Korea; ${ }^{3}$ Department of Otorhinolaryngology-Head and Neck Surgery, Korea Cancer Center Hospital, Seoul, Korea and ${ }^{4}$ Research Center for Radio-senescence, Korea Institute of Radiological and Medical Sciences, Seoul, Korea

${ }^{5}$ These authors contributed equally to this work.

Correspondence: Dr H Kwon, Division of Radiation Oncology, Korea Institute of Radiological and Medical Sciences, 75 Nowon-Gu, Nowon-Gu, Seoul 139-706, Korea. 


\section{MATERIALS AND METHODS}

\section{Isolation and culture of salivary gland-derived cells}

Human parotid and submandibular salivary glands were obtained during surgery at the Department of Otorhinolaryngology of Seoul National University Hospital. All aspects of this study were approved by the Ethical Committee of Seoul National University. The salivary glands were dissected under a microscope in Dulbecco's modified Eagle's medium (DMEM)/F12 medium containing 0.1\% collagenase type I and type IV (Sigma, St Louis, MO, USA). The suspended tissues were incubated for $20 \mathrm{~min}$ at $37^{\circ} \mathrm{C}$ on a shaker and then further treated with $1 \mu \mathrm{g} \mathrm{ml}^{-1}$ hyaluronidase for $20 \mathrm{~min}$ at $37^{\circ} \mathrm{C}$, followed by mechanical dissection and gentle pipetting. The resulting salivary gland cells were seeded in a T75 flask coated with collagen type I and cultured in DMEM/F12 1:1 (Invitrogen, Carlsbad, CA, USA) supplemented with $10 \%$ fetal bovine serum (FBS, Sigma), 1\% penicillin/streptomycin, 1\% insulin-transferrinselenium supplement (ITS-X, Gibco, Carlsbad, CA, USA), $10 \mathrm{~mm}$ nicotinamide, $100 \mathrm{~nm}$ dexamethasone, $1 \mathrm{~mm} \beta$-mercaptoethanol, $20 \mathrm{ng} \mathrm{ml}^{-1}$ hepatocyte growth factor (Prospec, East Brunswick, NJ, USA), $20 \mathrm{ng} \mathrm{ml}^{-1}$ Oncostatin $\mathrm{M}$ (Prospec), $1000 \mathrm{U} \mathrm{ml}^{-1}$ leukemia inhibitory factor (Chemicon, Billerica, MA, USA) and $20 \mathrm{ng} \mathrm{ml}^{-1}$ epidermal growth factor (Prospec). The medium was replaced every 3 days.

\section{Mesenchymal lineage differentiation}

Cells cultured for 10 passages were treated with adipogenic, osteogenic or chondrogenic medium for 3-4 weeks with change of medium twice weekly. The adipogenic medium consisted of DMEM supplemented with $10 \%$ FBS, $2 \mu \mathrm{M}$ insulin (Sigma), $500 \mu \mathrm{M}$ 3-isobutyl-1methylxanthine (Sigma), $1 \mu \mathrm{M}$ dexamethasone (Sigma), $200 \mu \mathrm{m}$ indomethacin (Sigma) and $2 \mu \mathrm{m}$ insulin. To evaluate differentiation, cells were fixed with $4 \%$ paraformaldehyde for $20 \mathrm{~min}$ at room temperature and stained with $0.5 \%$ Oil Red O in isopropanol for $30 \mathrm{~min}$ at room temperature. The osteogenic medium consisted of DMEM supplemented with $10 \%$ FBS, $0.1 \mu \mathrm{M}$ dexamethasone, $10 \mathrm{~mm}$ 3-glycerophosphate and $50 \mu \mathrm{g} \mathrm{ml}^{-1}$ ascorbic-2-phosphate (Sigma). Alizarin red staining was performed to confirm osteogenic differentiation. For chondrogenic differentiation, $2 \times 10^{5}$ hSGSCs were seeded onto a 24-well plate. Differentiation medium containing $0.1 \mu \mathrm{M}$ dexamethasone, $1 \mathrm{~mm}$ L-proline, $10 \mathrm{ng} \mathrm{ml}^{-1}$ transforming growth factor- $\beta 3$ (Sigma) and 1\% ITS was added to these cell pellets. To demonstrate the presence of glycosaminoglycans in specimens subjected to chondrogenic differentiation, we used Alcian Blue staining.

\section{Flow cytometry analysis}

Cells were washed three times with staining buffer (2\% FBS in phosphate-buffered saline) and then incubated with primary antibodies for $30 \mathrm{~min}$. The primary antibodies were fluorescein isothiocyanate-conjugated anti-CD49f (BD Biosciences, San Jose, CA, USA), R-Phycoerythrin (PE)-conjugated anti-CD90 (Ebioscience, San Diego, CA, USA), PE-conjugated anti-CD34, anti-CD44, antiCD45 and anti-CD 105 (BD Biosciences). Positively stained cells were quantified using a FACS Calibur Flow Cytometer (BD Biosciences), and data were analyzed using CellQuest software (BD Biosciences).

\section{Reverse transcriptase-PCR analysis}

Total cellular RNA was extracted using Trizol reagent (Invitrogen) according to the manufacturer's protocol. Complementary DNA was prepared from $500 \mathrm{ng}$ of total RNA by using Superscript II
(Invitrogen) with oligo-dT primers. The resulting complementary DNA was amplified using SWT-MX-BLC-7 (Esco Micro Pte Ltd., Seoul, Korea), and PCR products were electrophoresed in 1\% agarose and visualized using ethidium bromide staining (Supplementary Table S1).

\section{Differentiation of hSGSCs into amylase-expressing cells}

For differentiation of hSGSCs into amylase-expressing cells, a twostep differentiation was conducted. Differentiation medium 1 consisted of DMEM/F12 containing $1 \times$ ITS, $10 \mathrm{nM}$ dexamethasone, $10 \mathrm{ng} \mathrm{ml}^{-1}$ hepatocyte growth factor (HGF), $10 \mathrm{ng} \mathrm{ml}^{-1}$ epidermal growth factor (EGF), $10 \mathrm{ng} \mathrm{ml}^{-1}$ oncostatin $\mathrm{M}$ (OSM) and $0.1 \%$ dimethyl sulfoxide, and was applied to the cells for 7 days. Differentiation medium 2 consisted of DMEM/F12 containing $1 \times$ ITS, $10 \mathrm{~nm}$ dexamethasone, $10 \mathrm{ng} \mathrm{ml}^{-1}$ EGF and $0.5 \%$ dimethyl sulfoxide, and was applied to the cells for 14 days. To demonstrate the presence of amylase protein, we used immunocytochemistry with an anti-amylase antibody (Santa Cruz Biotechnology, Dallas, TX, USA).

\section{Animal experiments}

Male Wistar rats aged 6 weeks were used (Central Laboratory Animal Inc., Seoul, Korea). The head and neck area were irradiated with a single dose of 25 Gy using an X-RAD 320 X-ray irradiator (Precision X-ray Inc., North Branford, CT, USA) at a dose rate of $2 \mathrm{~Gy} \mathrm{~min}^{-1}$. After irradiation, animals were placed in a cage and given food and water ad libitum. One day after irradiation, $5 \times 10^{5} \mathrm{hSGSCs}$ per gland were transplanted. All experiments were performed under a protocol approved by the KIRAMS Animal Care and Use Committee.

\section{Histology}

For salivary gland histology, 5- $\mu$ m-thick paraffin-embedded tissues were routinely stained with hematoxylin and eosin (Merck, Darmstadt, Germany). Mucin and mucopolysaccharide-containing acinar cells were detected using periodic acid-Schiff's base.

\section{Terminal transferase-mediated dUTP nick-end labeling (TUNEL) assay}

Apoptotic cells in the salivary gland were evaluated using the ApopTag Peroxidase In Situ Apoptosis Detection Kit (Millipore, Billerica, MA, USA), which is based on the indirect TUNEL method, following the manufacturer's protocol. Tissue sections were deparaffinized, hydrated and incubated with a reaction mixture containing TdT enzyme for $1 \mathrm{~h}$ at $37^{\circ} \mathrm{C}$, and then incubated with the antidigoxigenin conjugate for $30 \mathrm{~min}$ at room temperature.

\section{Immunohistochemistry}

Immunohistochemistry was performed for the detection of human nuclei. Salivary gland sections were deparaffinized and subjected to antigen retrieval, and slides were blocked and labeled with a monoclonal anti-human nuclei antibody (Millipore) at a dilution of 1:100 dilution. Immunohistochemistry was performed according to the manufacturer's protocol using the Vectastain ABC Elite kit (Vector Laboratories, Burlingame, CA, USA) with diaminobenzidine-based visualization. Counterstaining was performed using hematoxylin.

\section{Statistical analysis}

Differences between samples were assessed using one-way analysis of variance for independent samples. A ${ }^{\star} P$ value of $<0.05$ was defined as statistically significant. 


\section{RESULTS}

Isolation and characterization of mesenchymal-like hSGSCs To effectively isolate and amplify stem cells in large amounts from human salivary glands, we developed a culture system with duration of 4-5 weeks. Single-cell suspensions obtained by mechanical and enzymatic dissociation of tissue obtained from adult human salivary glands were grown in our optimized culture media as described in the Materials and methods (Figure 1a). After isolation, adherent cells showed mainly fibroblast-like morphology that was largely maintained during passaging in monolayer culture (Figure $1 \mathrm{~b}$ ) and also high proliferation (Figure 1c). To confirm the phenotype of isolated salivary gland cell populations, we conducted immunofluorescent staining. After five passages, isolated primary salivary gland cells were consistently positive for typical human MSC surface antigen markers, such as CD44, CD49f, CD90 and CD105, which are known to participate in interactions with the extracellular matrix, whereas CD34 and CD45 were not expressed (Supplementary Figure S1). In addition, MSC marker expression in salivary gland stem cells (SGSCs) has been confirmed by flow cytometry (Figure 1d). These data suggest that hSGSCs can be isolated efficiently from the human salivary gland without requiring surface marker sorting, and the isolated cells express MSC surface markers.

\section{Differentiation of hSGSCs into three mesenchymal cell lineages}

To verify the MSC-like stemness of hSGSCs, we analyzed their differentiation into mesenchymal lineages in the presence of tissue-specific induction media. During culture in adipogenic medium, the morphology of cells gradually changed to a rounded shape, and fatty vacuoles were observed at day 21 of differentiation by Oil Red O staining (Figure 2a), whereas no fatty vacuoles were apparent in the undifferentiated condition (data not shown). Adipogenic gene expression was evaluated after induction. After 21 days of induction, proliferatoractivated receptor- $\gamma$ and lipoprotein lipase mRNA levels were slightly increased (Figure 2b). Osteogenic differentiation was evaluated by Alizarin red staining staining. Differentiated cells had spindle-like morphology after 21 days of induction, and almost the entire cell culture demonstrated positive staining (Figure 2c). Bone sialoprotein and osteocalcin mRNA levels were increased at day 21, but Runx2 mRNA levels did not change significantly (Figure $2 \mathrm{~d}$ ). To investigate chondrogenesis, salivary gland-derived cells were seeded into 48-well plates. Over time, pellets aggregated at the bottom of the plates. Chondrogenic differentiation was assessed by Alcian Blue staining to determine the amount of glycosaminoglycans and also by evaluating mRNA expression of aggrecan and collagen type II. As shown in Figures 2e and f, Alcian blue staining and chondrogenic aggrecan expression, but not collagen type II expression, were highly increased in differentiated MSCs. These data suggest that hSGSCs isolated using our technique have the capacity for differentiation into three mesenchymal lineages and are thus adult mesenchymal-like stem cells.

\section{Differentiation of hSGSCs into amylase-expressing salivary gland acinar cell lineage in vitro}

To determine whether MSC-like hSGSCs could differentiate into amylase-expressing cells, such as salivary gland acinar cells, we established a differentiation condition using several growth factors. hSGSCs were cultured under a two-step differentiation protocol for 21 days in vitro (Figure 3a). After differentiation, amylase expression was examined by western blot and reverse transcriptase-PCR (Figures $3 \mathrm{~b}$ and c). On day 21 , but not on day 7 , amylase was expressed at both the protein and mRNA levels. In addition, to further confirm amylase expression in the differentiated SGSCs, we performed
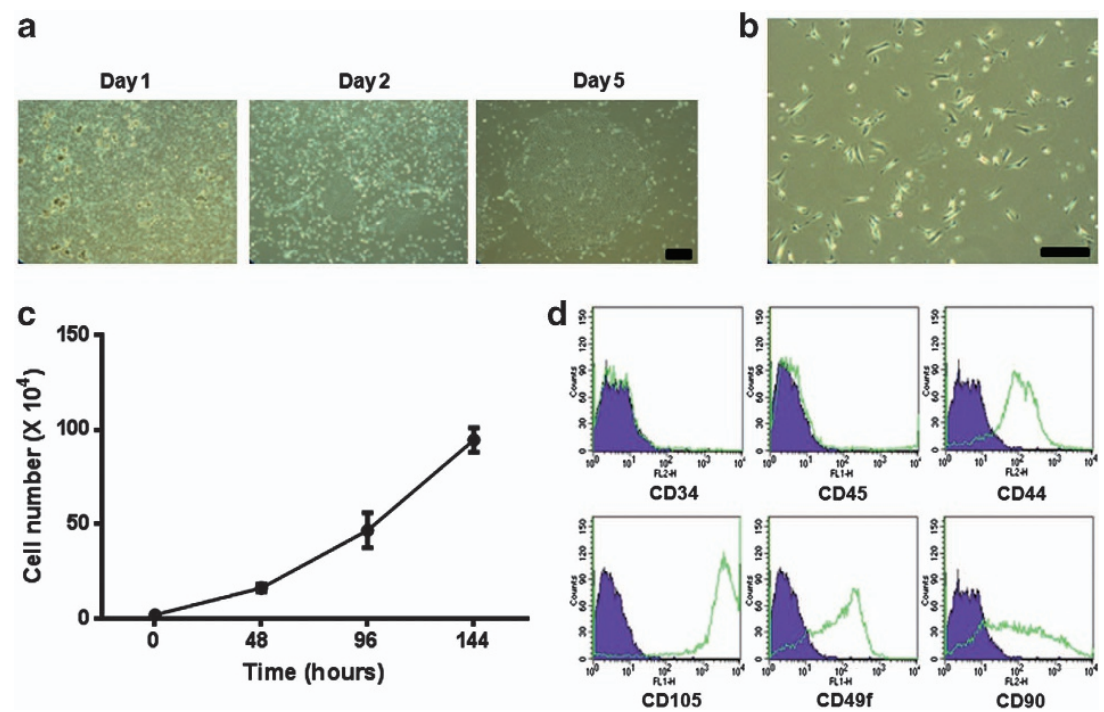

Figure 1 Human salivary gland stem cells (hSGSCs) were isolated from the normal human submandibular salivary gland. (a) Colony formation of hSGSCs with day. At day 5, a large single colony was formed. (b) Morphology of hSGSCs derived from the single colony under phase-contrast microscopy. (c) Proliferation assay. Isolated human salivary gland cells proliferated rapidly. (d) Isolated cells were evaluated with regard to cell surface marker expression by fluorescence-activated cell sorting. Bar, $100 \mu \mathrm{m}$. 


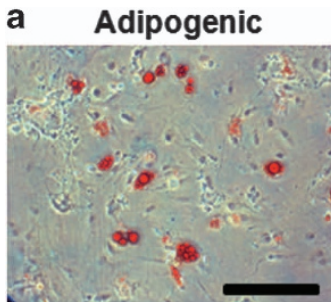

b

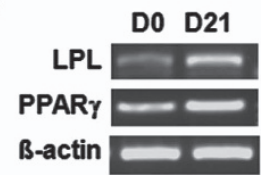

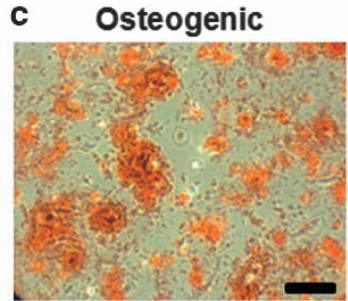

d

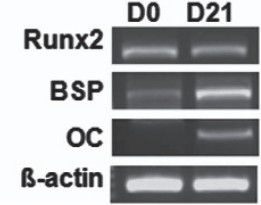

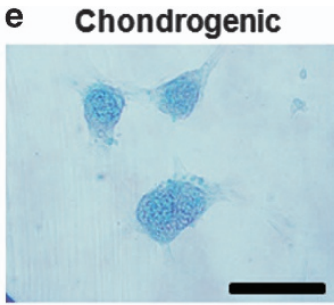

f

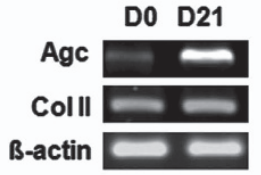

Figure 2 Human salivary gland stem cells (hSGSCs) have mesenchymal stem cell (MSC)-like differentiation potential. (a) Adipogenic differentiation of hSGSCs determined by staining with Oil Red O. (b) Adipogenic gene expression was confirmed by reverse transcriptasePCR (RT-PCR) after 3 weeks of differentiation. (c) Osteogenic differentiation of hSGSCs determined by staining with Alizarin Red. (d) Osteogenic gene expression was confirmed by RT-PCR after 3 weeks of differentiation. (e) Chondrogenic differentiation of hSGSCs determined by staining with Alcian Blue. (f) Chondrogenic gene expression was confirmed by RT-PCR after 3 weeks of differentiation. $\beta$-Actin was used as a loading control. Agc, aggrecan; BSP, bone sialoprotein; CollI, collagen type II; LPL, lipoprotein lipase; OC, osteocalcin; PPAR $\gamma$, proliferator-activated receptor- $\gamma$; Runx2, runt-related transcription factor 2. Bar, $200 \mu \mathrm{m}$.

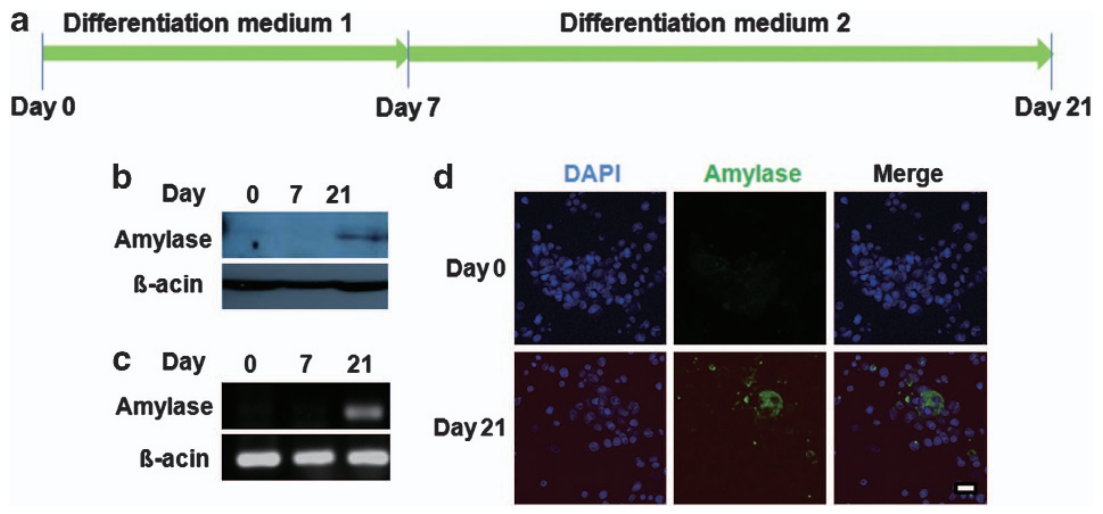

Figure 3 Human salivary gland stem cells (hSGSCs) were differentiated into amylase-expressing cells. (a) Experimental schedule for differentiation into amylase-expressing cells. (b) After 21 days of differentiation, amylase protein expression was detected by western blotting with an anti-amylase antibody. (c) After 21 days of differentiation, amylase RNA expression was detected by reverse transcriptase-PCR analysis. (d) Immunocytochemistry analysis was conducted to confirm amylase protein expression. Bar, $100 \mu \mathrm{m}$. DAPI, 4'-6-diamidino-2-phenylindole.

immunocytochemistry using an anti-amylase antibody. Amylase-expressing cells were found at day 21 (Figure $3 \mathrm{~d}$ ). These results suggest that the isolated MSC-like hSGSCs can be differentiated into acinar cells and potentially could be used for cell therapy of hyposalivation.

Amelioration of body weight loss and reduced saliva flow rate in radiation-damaged animals by transplantation of MSC-like hSGSCs

Isolated hSGSCs were differentiated into amylase-expressing cells as described above. To determine whether hSGSCs could improve salivary gland function and body weight loss in radiation-damaged rats, we transplanted $5 \times 10^{5}$ hSGSCs into the damaged salivary gland by intra-glandular injection and evaluated the body weight and saliva flow rate. Figure $4 \mathrm{a}$ shows that the body weight of radiation-damaged rats (IR + phosphate-buffered saline group) decreased gradually until day 7, after which it increased for 60 days. In the transplanted group (IR + hSGSCs), the body weight increased to a greater extent than it did in the phosphate-buffered saline group (Figure $4 \mathrm{a}$ ), and the saliva flow rate increased by twofold (Figure $4 \mathrm{~b}$ ). These findings support that transplantation of hSGSCs can functionally rescue the radiation-damaged salivary gland.

\section{Histopathological analysis of radiation-damaged salivary} gland tissue

We evaluated the salivary gland acinar and duct structure by hematoxylin and eosin staining, and we examined the composition of mucosubstances, such as glycoproteins, glycolipids and mucins, in the salivary gland by periodic acid-Schiff's base staining. The parenchyma of the salivary gland in untreated 

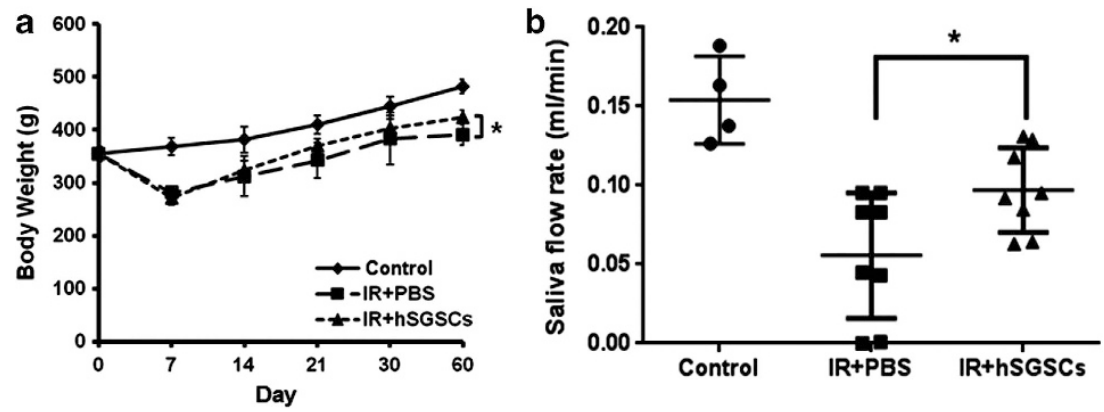

Figure 4 Salivary glands damaged by radiation were functionally regenerated by human salivary gland stem cell (hSGSC) transplantation. (a) Body weight loss was ameliorated by hSGSC transplantation at 60 days. (b) Saliva flow rate was measured at 60 days. The hSGSCtransplanted group showed increased saliva secretion relative to the phosphate-buffered saline (PBS)-treated group. $n=3$ with more than triplicate experiments; ${ }^{*} P<0.05$.
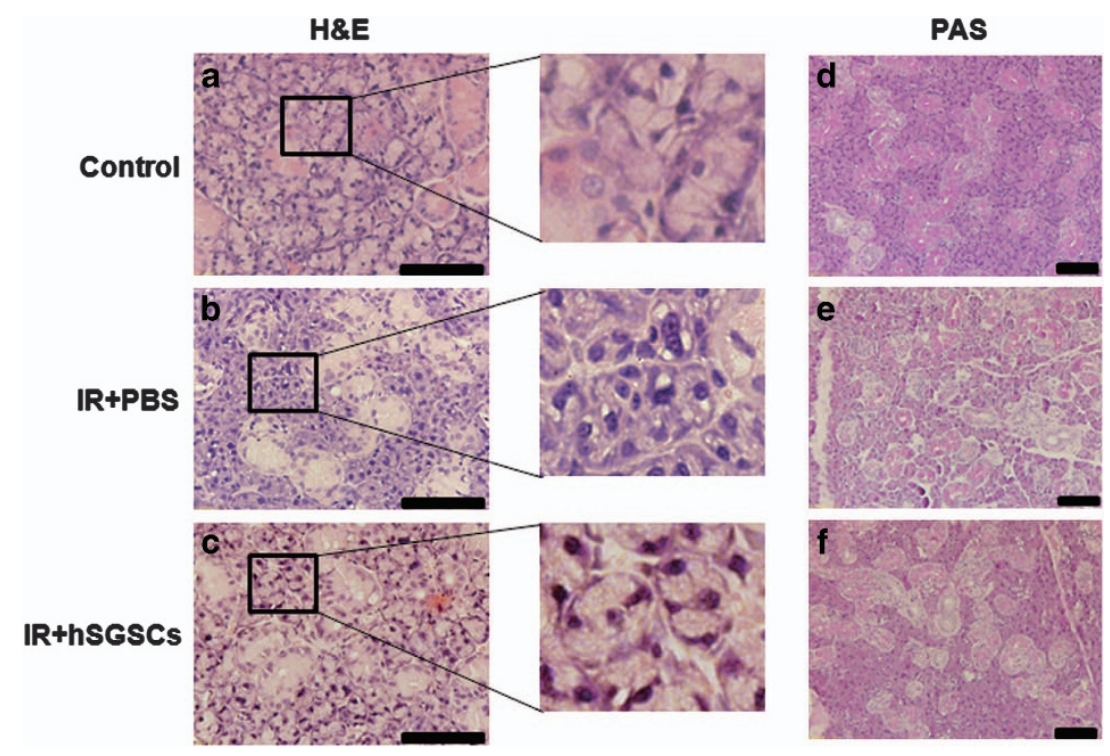

Figure 5 Histopathological analysis of radiation-damaged and intact salivary gland tissue. (a-c) Hematoxylin and eosin (H\&E) staining. The black box shows a magnified region. (d-f) Periodic acid-Schiff's base (PAS) staining. (a and $\mathbf{d}$ ) Intact control salivary gland. (b and $\mathbf{e}$ ) Irradiated salivary gland. (c and f) Human salivary gland stem cell (hSGSC)-transplanted irradiated salivary gland. Bar, $100 \mu \mathrm{m}$.

control rats was compact (Figure 5a). In contrast, numerous vacuoles and a disrupted acinar structure were present in irradiated salivary glands (Figure 5b). Rat salivary glands transplanted with hSGSCs showed a compact acinar structure similar to that of undamaged normal rat tissue (Figure $5 \mathrm{c}$ ). Similarly, mucosubstance distribution was also restored by hSGSC transplantation (Figures $5 \mathrm{~d}-\mathrm{f}$ ). To examine the inhibition of apoptosis by transplantation, we conducted the TUNEL assay. One week after irradiation of the salivary gland, the number of apoptotic cells increased substantially relative to the non-irradiated control (Figures $6 \mathrm{a}$ and $\mathrm{b}$ ), whereas apoptotic cells were not observed in the group transplanted with hSGSCs.

To determine whether the transplanted hSGSCs were successfully engrafted at the injected site, we performed immunostaining using the hNuclei antibody at 60 days posttransplantation. Transplanted hSGSCs were detected by the hNuclei antibody in the salivary gland tissue (Figures $6 \mathrm{~d}-\mathrm{f}$ ).
Taken together, these data demonstrate that radiationinduced damage of the salivary gland was ameliorated structurally and functionally by transplantation of mesenchymal-like hSGSCs.

\section{DISCUSSION}

To our knowledge, this study is the first to show a culture system of $4-5$ weeks for isolating hSGSCs without cell surface marker selection. We confirmed the therapeutic effect of these cells on radiation-damaged salivary gland hypofunction. Several groups have reported cell surface markers for isolation of hSGSCs. Sato, Rotter and Feng identified adult stem cells from the human salivary gland that expressed CD49 and Thy-1 and could be differentiated into pancreatic endocrine phenotype, had mesenchymal characteristics, and expressed c-kit, respectively. ${ }^{28-30}$ Recently, isolated MSCs have been suggested to contain heterogeneous cell populations; ${ }^{31-33}$ therefore, many researchers have isolated and purified MSCs by using 


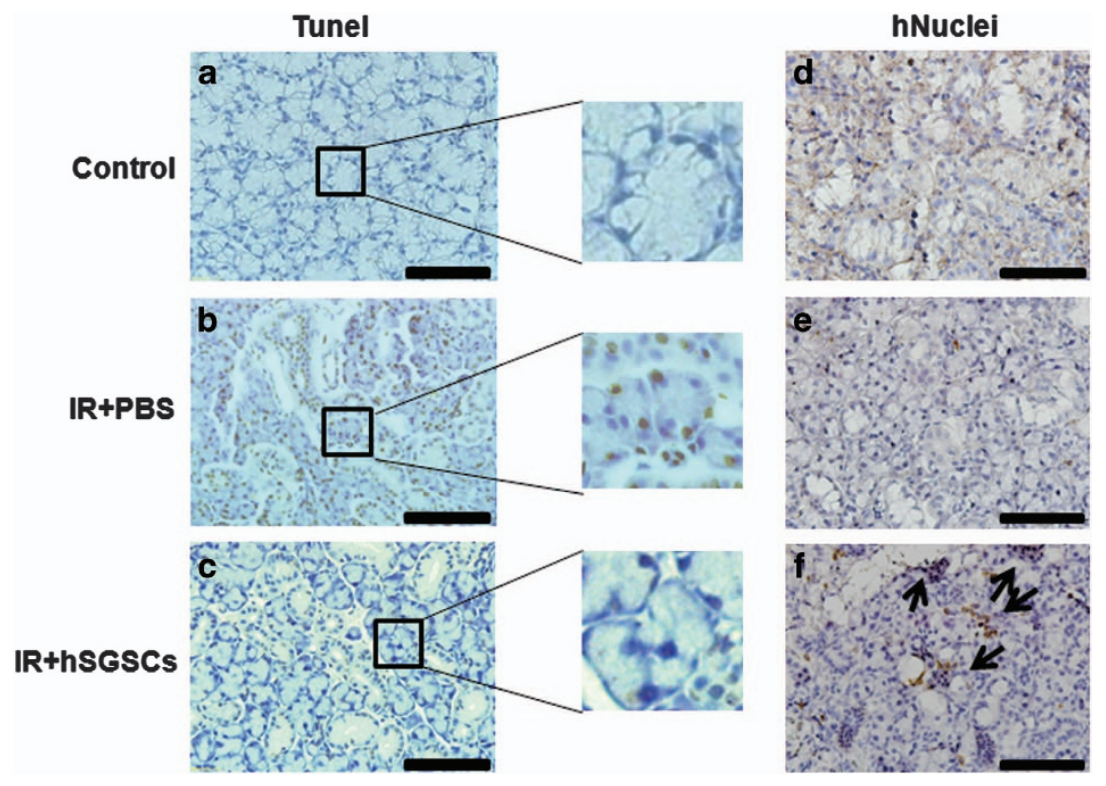

Figure 6 Human salivary gland stem cell (hSGSC)-transplanted tissues showed reduced apoptosis and engraftment of human cells. (a-c) Terminal transferase-mediated dUTP nick-end labeling (TUNEL) staining. The black box shows a magnified region. (d-f) Anti-human nuclei staining. (a and $\mathbf{d}$ ) Intact control salivary gland. (b and e) Irradiated salivary gland. (c and f) hSGSC-transplanted irradiated salivary glands. Bar, $100 \mu \mathrm{m}$. PBS, phosphate-buffered saline. The significance of arrows were not determined.

fluorescence-activated cell sorting. However, we obtained a homogenous cell population without marker sorting. Our homogeneously purified MSC-like SGSCs efficiently differentiated into three mesenchymal lineages (Figures $1 \mathrm{~b}$ and 2) and amylase-expressing cells (Figure 3).

To overcome radiation-induced hyposalivation, various therapeutic methods have applied in patients based on the use of cytokines or small molecules such as pilocarpine or amifostine to increase the secretion of saliva. ${ }^{34,35}$ However, pilocarpine treatment is associated with side effects, such as excessive sweating, chills, dizziness, excessive tearing, flushing, voice change, stuffy nose, tremor, nervousness and diarrhea. ${ }^{36,37}$ Adult stem cell therapy may provide an alternative without side effects. Recently, we isolated a population of $\alpha 6 \beta 1^{+} / \mathrm{c}$-kit ${ }^{+}$endodermal stem cells from rat salivary glands that could be differentiated into amylaseexpressing cells and pancreatic cells, ${ }^{38}$ and we demonstrated the regeneration potential of these cells after transplantation to radiation-damaged rat salivary glands. Therefore, adult stem cell transplantation may be useful for functional regeneration of radiation-damaged salivary glands.

In this study, we isolated highly proliferative and multipotent mesenchymal-like stem cells from the human salivary gland (hSGSCs), and showed that these cells ameliorated hypofunction of radiation-damaged salivary glands in rats after transplantation. Even though the isolation methods for hSGSCs are similar to those for rat endodermal SGSCs, the surface markers and differentiation capacities are different. For example, Thy-1, which is a marker for hematopoietic stem cells, ${ }^{39}$ MSCs, ${ }^{40}$ keratinocyte stem/progenitor cells ${ }^{41}$ and endometrial stem/progenitor cells, ${ }^{42}$ was not expressed by rat
SGSCs. In addition, rat SGSCs did not differentiate into three mesenchymal cell lineages (data not shown). Taken together, our findings therefore suggest that the major populations of stem cells able to regenerate of salivary gland tissue are different between humans and rats.

This is the first report of functional regeneration of salivary gland tissue by using salivary gland tissue-specific mesenchymal-like stem cells, although Rotter et al. isolated MSC-like stem cells from human parotid gland tissue for the first time in $2008 .{ }^{29}$ Further studies will address whether hSGSCs are useful for the treatment of other organs.

\section{CONFLICT OF INTEREST}

The authors declare no conflict of interest.

\section{ACKNOWLEDGEMENTS}

This work was funded by grants from the Nuclear Research and Development Program of the Korea Sciences and Engineering Foundation (KOSEF) funded by the Korean government (MEST, 2009-0093737).

1 de Almeida Pdel V, Gregio AM, Machado MA, de Lima AA, Azevedo LR Saliva composition and functions: a comprehensive review. J Contemp Dent Pract 2008; 9: 72-80.

2 Yeh CK, Johnson DA, Dodds MW. Impact of aging on human salivary gland function: a community-based study. Aging (Milano) 1998; 10: 421-428.

3 Dawson LJ, Smith PM, Moots RJ, Field EA. Sjogren's syndrome-time for a new approach. Rheumatology (Oxford) 2000; 39: 234-237.

4 Delporte C, O'Connell BC, He X, Lancaster HE, O'Connell AC, Agre P et al. Increased fluid secretion after adenoviral-mediated transfer of the aquaporin-1 cDNA to irradiated rat salivary glands. Proc Natl Acad Sci USA 1997; 94: 3268-3273. 
5 Guchelaar HJ, Vermes A, Meerwaldt JH. Radiation-induced xerostomia: pathophysiology, clinical course and supportive treatment. Support Care Cancer 1997; 5: 281-288.

6 Taylor SE. Efficacy and economic evaluation of pilocarpine in treating radiation-induced xerostomia. Expert Opin Pharmacother 2003; 4: 1489-1497.

7 Vissink A, Jansma J, Spijkervet FK, Burlage FR, Coppes RP. Oral sequelae of head and neck radiotherapy. Crit Rev Oral Biol Med 2003; 14: 199-212.

8 Langendijk JA, Doornaert P, Verdonck-de Leeuw IM, Leemans CR, Aaronson NK, Slotman BJ. Impact of late treatment-related toxicity on quality of life among patients with head and neck cancer treated with radiotherapy. J Clin Oncol 2008; 26: 3770-3776.

9 Ho KF, Farnell DJ, Routledge JA, Burns MP, Sykes AJ, Slevin NJ et al. Developing a CTCAEs patient questionnaire for late toxicity after head and neck radiotherapy. Eur J Cancer 2009; 45: 1992-1998.

10 da Silva Meirelles L, Chagastelles PC, Nardi NB. Mesenchymal stem cells reside in virtually all post-natal organs and tissues. J Cell Sci 2006; 119: 2204-2213.

11 Hare JM, Traverse JH, Henry TD, Dib N, Strumpf RK, Schulman SP et al. A randomized, double-blind, placebo-controlled, dose-escalation study of intravenous adult human mesenchymal stem cells (prochymal) after acute myocardial infarction. J Am Coll Cardiol 2009; 54: 2277-2286.

12 Kopen GC, Prockop DJ, Phinney DG. Marrow stromal cells migrate throughout forebrain and cerebellum, and they differentiate into astrocytes after injection into neonatal mouse brains. Proc Natl Acad Sci USA 1999; 96: 10711-10716.

13 Erices A, Conget $P$, Minguell JJ. Mesenchymal progenitor cells in human umbilical cord blood. Br J Haematol 2000; 109: 235-242.

14 Zuk PA, Zhu M, Mizuno H, Huang J, Futrell JW, Katz AJ et al. Multilineage cells from human adipose tissue: implications for cell-based therapies. Tissue Eng 2001; 7: 211-228.

15 Sabatini F, Petecchia L, Tavian M, Jodon de Villeroche V, Rossi GA, BroutyBoye D. Human bronchial fibroblasts exhibit a mesenchymal stem cell phenotype and multilineage differentiating potentialities. Lab Invest 2005; 85: 962-971.

16 Pittenger MF, Mackay AM, Beck SC, Jaiswal RK, Douglas R, Mosca JD et al. Multilineage potential of adult human mesenchymal stem cells. Science 1999; 284: 143-147.

17 Toma C, Pittenger MF, Cahill KS, Byrne BJ, Kessler PD. Human mesenchymal stem cells differentiate to a cardiomyocyte phenotype in the adult murine heart. Circulation 2002; 105: 93-98.

18 Shake JG, Gruber PJ, Baumgartner WA, Senechal G, Meyers J, Redmond $\mathrm{JM}$ et al. Mesenchymal stem cell implantation in a swine myocardial infarct model: engraftment and functional effects. Ann Thorac Surg 2002; 73: 1919-1925; discussion 26.

19 Gnecchi M, Zhang Z, Ni A, Dzau VJ. Paracrine mechanisms in adult stem cell signaling and therapy. Circ Res 2008; 103: 1204-1219.

20 Kinnaird T, Stabile E, Burnett MS, Shou M, Lee CW, Barr S et al. Local delivery of marrow-derived stromal cells augments collateral perfusion through paracrine mechanisms. Circulation 2004; 109: 1543-1549.

21 Mirotsou M, Zhang Z, Deb A, Zhang L, Gnecchi M, Noiseux N et al. Secreted frizzled related protein 2 (Sfrp2) is the key Akt-mesenchymal stem cell-released paracrine factor mediating myocardial survival and repair. Proc Natl Acad Sci USA 2007; 104: 1643-1648.

22 Phinney DG, Prockop DJ. Concise review: mesenchymal stem/multipotent stromal cells: the state of transdifferentiation and modes of tissue repaircurrent views. Stem Cells 2007; 25: 2896-2902.

23 Wagner W, Wein F, Seckinger A, Frankhauser M, Wirkner U, Krause U et al. Comparative characteristics of mesenchymal stem cells from human bone marrow, adipose tissue, and umbilical cord blood. Exp Hematol 2005; 33: 1402-1416.

24 Kern S, Eichler H, Stoeve J, Kluter H, Bieback K. Comparative analysis of mesenchymal stem cells from bone marrow, umbilical cord blood, or adipose tissue. Stem Cells 2006; 24: 1294-1301.
25 Li W, Ma N, Ong LL, Nesselmann C, Klopsch C, Ladilov Y et al. Bcl-2 engineered MSCs inhibited apoptosis and improved heart function. Stem Cells 2007; 25: 2118-2127.

26 Gaebel R, Furlani D, Sorg H, Polchow B, Frank J, Bieback K et al. Cell origin of human mesenchymal stem cells determines a different healing performance in cardiac regeneration. PLoS One 2011; 6: e15652.

27 Musina RA, Bekchanova ES, Belyavskii AV, Sukhikh GT. Differentiation potential of mesenchymal stem cells of different origin. Bull Exp Biol Med 2006; 141: 147-151.

28 Sato A, Okumura K, Matsumoto S, Hattori K, Hattori S, Shinohara M et al. Isolation, tissue localization, and cellular characterization of progenitors derived from adult human salivary glands. Cloning Stem Cells 2007; 9: 191-205.

29 Rotter N, Oder J, Schlenke P, Lindner U, Böhrnsen F, Kramer J et al. Isolation and characterization of adult stem cells from human salivary glands. Stem Cells Dev 2008; 17: 509-518.

30 Feng J, van der Zwaag M, Stokman MA, van Os R, Coppes RP. Isolation and characterization of human salivary gland cells for stem cell transplantation to reduce radiation-induced hyposalivation. Radiother Oncol 2009; 92: 466-471.

31 Vogel W, Grunebach F, Messam CA, Kanz L, Brugger W, Buhring HJ. Heterogeneity among human bone marrow-derived mesenchymal stem cells and neural progenitor cells. Haematologica 2003; 88: 126-133.

32 Wagner W, Feldmann RE Jr., Seckinger A, Maurer MH, Wein F, Blake J et al. The heterogeneity of human mesenchymal stem cell preparationsevidence from simultaneous analysis of proteomes and transcriptomes. Exp Hematol 2006; 34: 536-548.

33 Ho AD, Wagner W, Franke W. Heterogeneity of mesenchymal stromal cell preparations. Cytotherapy 2008; 10: 320-330.

34 Lombaert IM, Brunsting JF, Wierenga PK, Kampinga HH, de Haan G, Coppes RP. Cytokine treatment improves parenchymal and vascular damage of salivary glands after irradiation. Clin Cancer Res 2008; 14: 7741-7750.

35 Burlage FR, Faber H, Kampinga HH, Langendijk JA, Vissink A, Coppes RP. Enhanced proliferation of acinar and progenitor cells by prophylactic pilocarpine treatment underlies the observed amelioration of radiation injury to parotid glands. Radiother Oncol 2009; 90: 253-256.

36 Taweechaisupapong S, Pesee M, Aromdee C, Laopaiboon M, Khunkitti W. Efficacy of pilocarpine lozenge for post-radiation xerostomia in patients with head and neck cancer. Aust Dent J 2006; 51: 333-337.

37 Hamlar DD, Schuller DE, Gahbauer RA, Buerki RA, Staubus AE, Hall J et al. Determination of the efficacy of topical oral pilocarpine for postirradiation xerostomia in patients with head and neck carcinoma. Laryngoscope 1996; 106: 972-976.

38 Baek H, Noh YH, Lee JH, Yeon SI, Jeong J, Kwon H. Autonomous isolation, long-term culture and differentiation potential of adult salivary glandderived stem/progenitor cells. J Tissue Eng Regen Med (e-pub ahead of print 23 August 2012; doi:10.1002/term1572).

39 Craig W, Kay R, Cutler RL, Lansdorp PM. Expression of Thy-1 on human hematopoietic progenitor cells. J Exp Med 1993; 177: 1331-1342.

40 Majeti R, Park CY, Weissman IL. Identification of a hierarchy of multipotent hematopoietic progenitors in human cord blood. Cell Stem Cell 2007; 1: 635-645.

41 Nakamura Y, Muguruma Y, Yahata T, Miyatake H, Sakai D, Mochida J et al. Expression of CD90 on keratinocyte stem/progenitor cells. Br J Dermatol 2006; 154: 1062-1070.

42 Gargett CE. Identification and characterisation of human endometrial stem/progenitor cells. Aust N Z J Obstet Gynaecol 2006; 46: 250-253.

(c) (1) $(9)$ This work is licensed under a Creative Commons
Attribution-NonCommercial-NoDerivs 3.0 Un-
ported License. To view a copy of this license, visit http://
creativecommons.org/licenses/by-nc-nd/3.0/

